\title{
Aporte para uma Hermenêutica em Psicologia Escolar
}

Contribution for hermeneutic in the school psychology

Elbio Nelson

Cardoso Guardia

Universidade da

República Oriental do

Uruguai 


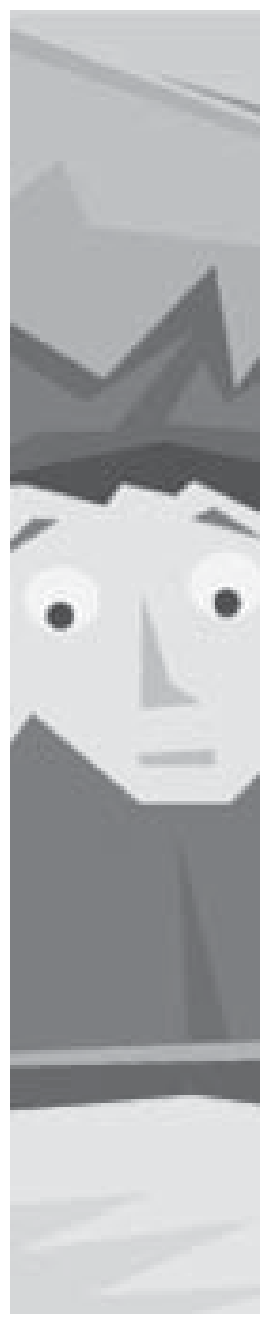

Resumo: Este artigo busca colocar em pauta para debate o valor metodológico que pode ter a hermenêutica, enquanto instrumento epistemológico, quando aplicada à área de Psicologia escolar e a utilidade da técnica de observação participante no contexto de uma metodologia qualitativa de pesquisa, realizada na escola pública. Para a análise das informações contidas no diário de campo e nas entrevistas, utilizamos a análise de conteúdo para lograr uma leitura que venha a realçar o aspecto multidimensional das dificuldades de aprendizagem, as características da comunicação e dos comportamentos dos alunos, professoras, psicólogas e do próprio pesquisador. Na fase de interpretação das categorias, procura-se captar o sentido da experiência do encontro com o outro e a atuação do psicólogo no campo da saúde coletiva, utilizando como base a compreensão existencial.

Palavras-chave: Psicologia escolar, acompanhamento in situ, empatia.

Abstract: This article tries to bring out for debate the methodological value that hermeneutic can have as an epistemological instrument when applied in the area of school Psychology and the usefulness of the participant observation technique in the context of a qualitative methodology of research accomplished in the public school. For the analysis of the information contained in the daily report book and in the interviews, it was used the content analysis to achieve a sight that comes to enhance the multidimensional aspect of the learning difficulties, the characteristics of the communication and of the students, teachers, psychologists and the own researchers behavior. In the stage of the categories interpretation, it tries to bring up the sense of experience from the contact with others and the psychologist's performance in the collective health field, using the existential understanding as base.

Key words: school Psychology, participant observation, hermeneutic.

De modo geral, no Brasil, o psicólogo, quando trabalha na escola oficial, defronta-se com os problemas acarretados pelo fracasso escolar e o mal-estar deles decorrentes, que atingem as famílias e os professores em sala de aula. Diante de tal situação, sem muitas opções, esse profissional é levado, pela tradição, a adotar um enfoque institucional no manejo e na compreensão das dificuldades de aprendizagem, limitando-se a assessorar os professores com uma escuta psicanalítica, encaminhando os alunos "atípicos" para psicoterapia com psicólogos credenciados ou atuantes em postos de saúde, ou para atendimento psicopedagógico clínico. Nas escolas municipais de Porto Alegre, em particular, o trabalho do psicólogo está praticamente circunscrito à supervisão de escolas especiais e às professoras de Educação Especial, encarregadas das salas de integração e recursos (SIR), destinadas a facilitar a integração, nas escolas regulares, dos alunos com necessidades educativas especiais e com dificuldades de aprendizagem.

\section{Qual a eficácia dessas abordagens?}

Sabe-se que, em se tratando de alunos de periferia, nenhuma dessas medidas têm eficácia comprovada.

\section{Problema de pesquisa}

É possível falar em atendimento psicológico adequado para alunos que, por um motivo ou 
outro, sofrem o fracasso escolar crônico na escola pública que adota uma abordagem institucional, conforme evidenciado na Rede Municipal de Educação em Porto Alegre?

Em contraponto a essa problemática, primeiro buscamos, pela hermenêutica, contextualizar o problema de pesquisa e, numa segunda instância, descobrirmos possibilidades heurísticas a partir da experimentação de campo, embasada no marco conceitual da saúde coletiva. Com efeito, esta investigação advém da possibilidade que brinda a hermenêutica, na sua acepção moderna, entendida como um processo dialético entre a compreensão e a interpretação, e do qual emerge um sentido, necessariamente, inserido em um contexto histórico social, e de saúde coletiva, por permitir manejar o conceito de campo e de valor social e existencial quando nos referimos à categoria doença e saúde. Ambas permitiram-nos conduzir uma forma de produção de conhecimento desvinculada da praxe usual, ligada à escuta e ao enquadramento, recomendado pela intervenção em Psicologia clínica, em Psicopedagogia, em Pedagogia e em Psicologia escolar, na sua vertente tecnicista ou institucional.

\section{Contextualização do problema de pesquisa}

O campo epistemológico que investigamos está vinculado à história da formação de determinadas práticas sociais e construtos teóricos, que têm influenciado, direta ou indiretamente, a configuração de uma formação universitária incompleta em Psicologia escolar e no magistério e, conseqüentemente, a atuação do psicólogo e do professor em nosso meio, distante da realidade dos alunos de periferia considerados "diferentes". Trata-se de estratégias míticas ou concretas, postas em prática pela Tradição, pela Política, pela Medicina, pela Educação e pela Psicologia para alcançar, em cada época, perfis de homem, assim como do itinerário de determinadas contingências sociohistóricas que têm provocado o surgimento espontâneo ou calculado de práticas sociais e de construtos ideológicos, revestidos de "jogos de verdade", de desvelos fraternais ou de franca hipocrisia em áreas da educação e da saúde individual e coletiva. Na verdade, no cerne dessas questões, há uma compreensão ufana, que instrumenta ações, remédios preventivos e curativos para os problemas das crianças pobres em fase de escolarização. Essa soberba ocorre, sempre, no campo da ciência das sociedades modernas por estarem estas ligadas, direta ou indiretamente, ao poder disciplinar (Foucault, 1981; 1999).

Nesse contexto epistemológico, os problemas que interrogamos, em relação aos alunos de periferia que freqüentam a escola pública em nosso país, originam-se no Brasil Colônia. A diferença de posição social entre o branco colonizador europeu e a população nativa, negra e mestiça, assim como a economia, baseada na grande propriedade e na mão-deobra escrava, sob o domínio do poder da família patriarcal, criavam, mediante a obra dos jesuítas, condições favoráveis para a importação das idéias dominantes da cultura medieval européia e de um modelo de ensino escolástico, acadêmico e aristocrático, destinado às classes sociais dominantes (Romanelli, 2001), e sobre a qual se formaria o sistema educativo brasileiro.

O processo de exclusão de certas camadas da sociedade vai complementar-se, no final do século XVIII e início do século XIX, com um fenômeno chamado por Foucault (1999) de "ortopedia social" em razão da utilização discriminada de métodos corretivos disciplinares, de vigilância e controle, e por ser uma época em que o controle social dos indivíduos se aperfeiçoa por meio de uma série de instituições pedagógicas, médicas, psicológicas, psiquiátricas e policiais, tendo como objeto de atenção, principalmente, as crianças durante a primeira infância (Enguita, 1989), mas que se estenderá, também, aos 
loucos, aos pobres e às prostitutas. No campo da Educação, deslocou-se o interesse religioso para a disciplina material e para a organização meticulosa da experiência escolar. Aspectos da disciplina monástica passaram a ser aplicados, no decorrer do século XVIII, nas escolas, fábricas e quartéis, configurando uma nova "microfísica do poder" mediante um investimento político, cada vez maior, na importância dos arranjos disciplinares, desde os mais sutis até dispositivos de inspeção, que centram sua atenção em minúcias e detalhes aparentemente inofensivos, mas que resultarão no quadro específico da escola elementar, pela ordenação dos alunos por fileiras, em sala de aula, nos corredores, nos pátios, nas avaliações dos alunos em relação a cada tarefa, sucessão de assuntos ensinados, exercícios em ordem de dificuldade crescente, entre outros. É nesse contexto disciplinar que a criança, o louco, o condenado e o doente serão, a partir do século XVIII, objeto de descrições individuais e de relatos biográficos ; cada um receberá a caracterização de sua própria individualidade, ligada aos traços, às medidas, aos desvios, às notas.

No Brasil, o nascimento da psiquiatria, durante o século XIX, realiza-se no seio da Medicina social, que incorpora a sociedade como objeto de estudo, desenvolvendo instâncias de controle social dos indivíduos e das populações. A psiquiatria terá, como primeiro alvo de investigação, o louco pobre (os ricos eram isolados, alimentados e tratados, em quartos fechados, em suas próprias casas), considerado potencialmente perigoso para a moral pública e a segurança, sendo, por esse motivo, retirado das ruas e levado para o Hospital da Santa Casa de Misericórdia, lugar para onde iam os "alienados" antes da construção do Hospício, por D. Pedro II, em 1841, no Rio de Janeiro (Machado, 1978). No Rio Grande do Sul, os excluídos foram os "gaúchos", mestiços que viviam de "prear" gado para as charqueadas. Eles se sentiram, de repente, fora das trocas sociais e econômicas porque ineptos para acomodarse à demanda da nova ordem capitalista e competir com a mão-de-obra dos imigrantes europeus, trazidos, especialmente, pelos portugueses para explorar a agricultura e trabalhar na incipiente indústria de manufatura. Passaram a ser considerados "gentalha", "ralé" que ameaçava os centros urbanos. O Hospício São Pedro, em Porto Alegre, desde 1984, tem cumprido seu papel sob o olhar da Medicina Social, e foi de seu feitio absorver os "excluídos" da nova ordem capitalista; esse manicômio conheceu todos os tratamentos possíveis para a loucura: exclusão do convívio social, tratamento moral, colônia agrícola, sangria, insulinoterapia, eletrochoque, farmacologia, castigos.

A Medicina escolar (Lima, 1985) brasileira teve, também, participação nesse processo de normalização e, junto com a Educação, construíram estereótipos (Jeca Tatu), traços distintivos característicos de doenças para identificar a condição de ser brasileiro. Nessa perspectiva, o caboclo, o sertanejo, os grupos marginalizados da sociedade e o "espírito" do homem brasileiro, em geral, passaram a ser sinônimos de abandono e doença.

Um outro aspecto que tem influído na falta de elucidação do fracasso escolar dos alunos de periferia e complicado as intervenções propostas pela área da Psicologia escolar é a ambigüidade com que se maneja o termo "dificuldades de aprendizagem". No Brasil, primeiramente, foi utilizada a expressão distúrbios de aprendizagem para sugerir que havia a existência de uma doença sofrida pelo aluno. Logo, essa expressão passou a ser utilizada pelos professores para referir-se ao fracasso escolar, no sentido médico, mesmo sem saber os critérios ou o significado etimológico. Do mesmo modo, utiliza-se, até hoje, o termo hiperativo, dislexia, hipercinético para designar problemas de escolarização. Essas interpretações acabam dando uma origem biológica a um problema mal conhecido ou, fundamentalmente, social.
Um outro aspecto que tem influído na falta de elucidação do fracasso escolar dos alunos de periferiae complicado as intervenções propostas pela área da Psicologia escolar é a ambigüidade com que se maneja o termo "dificuldades de aprendizagem". 
Posteriormente, os distúrbios de aprendizagem passam a ser chamados de dificuldades de aprendizagem, mas, para Moysés e Collares (1992) e Moysés e Lima (1982), continua sendo uma construção do pensamento médico. Ambas as denominações surgiram como entidades nosológicas e persistem, assim, como "doenças" neurológicas em razão do costume de dar novas máscaras a velhas idéias, por culpa do "raciocínio clínico tradicional" assim como pela facilidade com que a sociedade brasileira aceita as formas de

Essa forma de compreender o mal-estar que acomete o homem inserido na Cultura, por parte do psicólogo escolar, transparece na visão tecnicista que ele tem do fracasso escolar, na sua prática compartimentada em relação aos profissionais da saúde e da educação e na opinião de que as dificuldades de aprendizagem pertencem ao campo da Educação Especial e da Psicopedagogia. controle, a medicalização e a patologização das condutas desviantes.

Esses termos, quando vinculados ao fracasso escolar, permitem que se dêem explicações as mais variadas, desde fenômenos macropolíticos até conjeturas, baseadas em critérios "científicos" que responsabilizam o sujeito que não aprende e na sua condição de vida precária. Sendo assim, cria-se um universo para o qual conflui uma variedade desorganizada de teorias e tratamentos, tornando-se difícil distinguir o que é normal ou defeito. O mais grave de tudo é que o aluno, facilmente, passa de um estado normal para o patológico...

O impasse epistemológico, apresentado pelas múltiplas conotações que pode ter a expressão "dificuldades de aprendizagem", reflete-se, também, no âmbito da Psicologia escolar, em particular, na falta de discernimento no campo da saúde coletiva com que o psicólogo tem orientado sua prática profissional em relação à complexidade do tema. Por um lado, o profissional da área vê-se impelido a moverse num campo ambíguo, entre uma defectologia e a normalidade, contando com poucos recursos porque adquiriu, desde cedo, com a Medicina, a psiquiatria e a psicanálise, um viés de enquadramento clínico, esquecendo-se de que a realidade da vida de um sujeito é atravessada não somente pelas fantasias inconscientes mas também por fatores sociohistóricos. Essa forma de compreender o mal-estar que acomete o homem inserido na Cultura, por parte do psicólogo escolar, transparece na visão tecnicista que ele tem do fracasso escolar, na sua prática compartimentada em relação aos profissionais da saúde e da educação e na opinião de que as dificuldades de aprendizagem pertencem ao campo da Educação Especial e da Psicopedagogia.

Somam-se aos problemas antes mencionados muitas contradições e ambigüidades evidentes nos projetos de intervenção e, mais ainda, os desafios para alcançar uma identidade profissional por causa de sua incipiente regulamentação institucional, por ser uma ciência jovem que pugna por ser sui generis, em nosso meio, praticamente sem nenhuma tradição de pesquisa e fundamentação epistemológica, e pelo hiato mantido por esse profissional com a realidade social da escola pública brasileira.

A pesquisa educacional das dificuldades de aprendizagem, sob a influência de modelos estrangeiros nos temas de pesquisa, também se imbuiu do olhar tecnocrático que entende o fracasso escolar como um problema pessoal do aluno e de sua família. As conjeturas de alguns pesquisadores (Poppovic, 1968; Bonamigo e Bristoti, 1978; RamozziChiarottino, 1982; Montoya, 1983) formaram uma representação sobre os problemas escolares dos alunos da escola pública que se refletiram na oscilação dos posicionamentos que se estabelecidos, em distintas épocas, entre teoria, pesquisa e política educacional, no Brasil, e que tiveram influência na criação de creches, instituições de ensino pré-primário e no modo como o fracasso escolar, nas primeiras séries do ensino fundamental, principalmente das camadas pobres da sociedade, passou a ser visto e tratado de maneira espúria por especialistas e professores.

\section{Experimentação de campo}

Foi necessário sentirmo-nos menos ingênuos para praticar o "amor facti" de que fala Nietzche: 
o acolhimento do inesperado, escutando outras vozes apenas ouvidas e permanecendo abertos para o outro, que vem ao nosso encontro e nos desaloja da indiferença, com a consciência inquieta pela urgência de trabalhar para que surjam novas perspectivas à opinião arraigada de que as dificuldades dos alunos são, irremediavelmente, formações inconscientes ou de funcionamento deficitário, relacionados à pobreza econômica e cultural ou à ideologia do sistema capitalista. Implicou, vamos dizer, contestar a prática comum de que esse aluno deve ser encaminhado e tratado no consultório ou em escolas especiais, porque vamos progredir muito pouco como psicólogos enquanto o nosso labor permanecer compartimentado.

Para descobrir o sentido do mundo da escola e de seus alunos com dificuldades de aprendizagem no seu todo, buscamos apreender a condição fática dos participantes da pesquisa sem separarmo-nos da trama de conceitos e das relações de poder que conformam o contexto histórico-social e, para isso, realizamos uma experimentação de campo que segue o paradigma de pesquisa naturalística ou construtivista. Tal paradigma define uma lógica a ser acionada pelo pesquisador que permite a utilização de uma metodologia qualitativa de pesquisa de natureza etnográfica, visando à descrição, compreensão e interpretação do significado das dificuldades primárias de aprendizagem para o aprendizado escolar no contexto da escola pública. Buscase o conhecimento mediante a participação do pesquisador num movimento dialético de engajamento sensível e intuitivo com o mundo vivido pelos sujeitos da pesquisa. Nesse sentido, fomos, além da relação com os alunos, trabalhar com a professora de sala de aula e a da Sala de Integração e Recursos (SIR) na escola pesquisada e com a família dos alunos, quando possível, por serem esses elementos constitutivos do universo imediato do aluno.

\section{Campo de ação}

O trabalho de campo foi realizado em uma escola localizada num bairro de periferia, do Município de Porto Alegre, no período de março a dezembro de 1999. É uma escola de ensino fundamental que, à época da realização da pesquisa, adotava a seriação como modelo curricular. Posteriormente, passou a adotar o modelo de ciclos e de salas de progressão, proposto pelo projeto Escola Cidadã .

À época do trabalho de campo, a escola se encontrava em fase de preparação para a implantação desse modelo escolar. Dentro dessa escola, o pesquisador efetuou o trabalho de campo em diversos ambientes: sala de aula, pátio, biblioteca e Sala de Integração e Recursos (SIR).

Participantes da pesquisa

Os alunos tinham idades entre dez (10) e quatorze (14) anos, e tinham sido colocados na mesma sala, junto a outros alunos, formando uma classe com vinte e cinco (25) estudantes de segunda série do ensino fundamental. Os cinco (5) alunos pesquisados (uma aluna constituía exceção, pois recaia sobre ela suspeita de síndrome de Down), eram multirrepetentes, e esse fracasso escolar foi vinculado às dificuldades primárias de aprendizagem, isto é, às dificuldades de aprendizagem não relacionadas a distúrbios neurológicos ou a deficiências sensoriais evidentes. Esses alunos, mesmo tendo dificuldades de leitura, de escuta, disortografia ou discalculia, não poderiam ser incluídos nos quadros que compõem os "distúrbios de aprendizagem secundários" (Fonseca, 1995), 
como deficiências sensoriais, motoras ou de comunicação.

\section{Coleta de informações e instrumentos}

As informações coletadas foram de diversas fontes: consulta de fichas escolares; relatos verbais; diário de campo e entrevistas gravadas, elaboradas, seguindo a técnica de perguntas orientadas, com a orientadora educacional e as professoras de educação especial (SIR) e com as psicólogas que assessoram a escola pesquisada, lotadas na Secretaria Municipal de Educação, em Porto Alegre.

\section{Tratamento do Material}

Para o tratamento das informações, seguimos as fases propostas pela análise de conteúdo para a análise temática (Bardin, 1977): usamos um processo de indução para dar significação e categorizar os dados coletados por meio da observação participante, registrados no diário de campo e nas entrevistas gravadas com professoras e psicólogas. Esse modo abrangente e multidimensional de focar o tema, mediante trabalho participativo em campo, é diferente da técnica conhecida como "análise da interação", aproximando-se mais da técnica utilizada pelo método etnográfico descrito por Malinowski (1984), que se imbui de uma visão "antropológica" e valoriza o processo de inferência, decorrente do uso de indicadores qualitativos, constituídos com base na observação participante. Essa metodologia possibilitou, dessa maneira, descobrir a escola e a sala de aula como um lugar socialmente estruturado mediante várias redes de significação. A forma de coletar os achados e de construir o conhecimento científico por meio da relação de proximidade com os participantes de pesquisa caracteriza-se como um estudo de caso dessa investigação, pelo modo de apreender, em profundidade, as experiências e vivências dos agentes sociais que constroem o cotidiano escolar.

É necessário dizer, também, que a hermenêutica adquire, para nós, um valor metodológico-fenomenológico em relação aos objetivos seguintes: 1.Descrever, no ambiente da escola pública em Porto Alegre, momentos da dinâmica interativa do cotidiano escolar dos alunos com dificuldades primárias de aprendizagem; 2. Compreender a dinâmica de interação dos participantes da pesquisa e das professoras em situação sociopedagógica; 3. Interpretar, com base na hermenêuticaexistencial, a situação dos alunos com dificuldades primárias de aprendizagem.

Esse olhar multidimensional pela hermenêutica, como modo de investigação e reflexão, impôs-se-nos como uma necessidade para poder problematizar o labor do psicólogo na escola pública e vir a compreender sua atuação no campo da saúde coletiva. O campo coletivo, atualmente, investiga o fenômeno saúde-doença não somente apoiando-se em uma epistemologia científica mas também, em uma filosofia que sirva de substrato comum para apreender o homem como ser existente, que se realiza na existência, seja na doença, no sofrimento de uma perda ou no mal-estar causado por sua condição de exclusão social. Buscamos, enfim, compreender os participantes da pesquisa como "seres-nomundo", como Dasein, e, a partir de um lugar hermenêutico e por meio de instrumentos teóricos e práticos, buscamos investigar e aproximar-nos da escola e desse pequeno mundo que constitui a sala de aula, onde o aluno e o professor existem de determinada maneira que se destaca como um espaço relacional diferente de qualquer outro enquadramento. 
Tabela 1 - Interpretação e discussão das categorias

\section{Unidades de significação}

Abordagem institucional das dificuldades de aprendizagem;

Visão tecnicista do fracasso escolar;

Atuação dos profissionais de saúde e da educação vista de maneira compartimentalizada;

As dificuldades de aprendizagem pertencem ao campo da Educação Especial e da Psicopedagogia;

\section{Categorias}

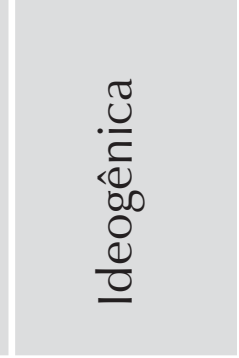

Inibição dos movimentos;

Baixa auto-estima dos alunos;

Simulação e silêncio por parte dos alunos inibidos;

Ausência de demanda de ajuda;

Angústia;

Mecanismo de defesa fóbico por parte dos alunos;

Perturbação da comunicação entre as professoras e os alunos inibidos;

Compreensão mais apurada dos problemas dos alunos;

Demanda de ajuda por parte dos alunos pesquisados;

Disposição para ajudar por parte das professoras;

Atribuição de um sentido diferente às relações interpessoais

e à aprendizagem escolar;

Desinibição dos alunos em sala de aula;

Comunicação;

Mudanças na expressão gráfica e plástica dos alunos na SIR.

\section{Classificação e construção de categoria}

A categoria "ideogênese" diz respeito à situação "marginal" dos alunos de periferia, à escola pública e ao tema das dificuldades de aprendizagem. O modo característico de laborar dos psicólogos vinculados à escola pública brasileira é objeto de crítica por parte de diversos estudiosos. Uma das coisas assinaladas é o franco distanciamento desses profissionais da realidade escolar por causa da maneira tecnocrática de compreender e intervir sobre as dificuldades de aprendizagem e dos problemas emocionais decorrentes que afetam as crianças de periferia, famílias e professoras.

$\mathrm{Na}$ verdade, o que pretendemos, ao acompanhar a criança na escola, é atuar modificando o instituído, buscando a dimensão coletiva em Psicologia escolar, que vai realizarse na medida em que diminuímos a distância com o aluno. Essa questão, também, foi dirigida ao psiquiatra quando este procurou um modo alternativo de terapêutica a fim de lograr 
Se, no caso, o trabalho de quem presta ajuda aos alunos com "problemas escolares" partisse da premissa do conflito entre mundos, a compreensão que ele vai ter sobre as dificuldades de aprendizagem ou da enfermidade mental, por exemplo, vai ser diferente. o estabelecimento de serviços comunitários de saúde mental. Ele teve que sair ao encontro da comunidade e comprometer-se, ideologicamente, com a realidade social; foiIhe preciso assimilar os conhecimentos de outras disciplinas das ciências humanas, como a Antropologia Cultural, Sociologia, Psicologia, psicanálise, Filosofia da prática. Na medida em que isso ocorria, o psiquiatra foi perdendo os preconceitos de classe e de raça (Busnello, 1975).

O mesmo pode-se dizer da Psicologia em comunidade, pelo menos do ímpeto que animou o psicólogo desde meados da década de 60, quando esse profissional passa a atuar mais próximo às comunidades.

No campo da saúde coletiva, poder-se-ia considerar a atuação do psicólogo como agente de saúde, promovendo a saúde, desvencilhado do modelo subjetivistaindividualista e do modo de conceber a subjetividade à margem das condições concretas de vida. Baremblitt (1991), ao referir-se ao trabalho do acompanhante terapêutico, diz que o essencial é o encontro com as pessoas; temos que abdicar da necessidade de recorrer ao artifício de ocupar "o lugar do morto" (refere-se ao silêncio mantido pelo analista), recusando, sempre, a demanda do outro para mostrar-lhe que a falta do ser existe. Devemos, enfim, deixar de pensar que nosso ego é feito apenas de palavras e de imagem especular.

Esse autor referido propõe a compreensão do sofrimento humano com base no conceito ser no mundo como significado de um sujeito que produz mundos. Para entendermos porque se geram marcas e estigmas que produzem os comportamentos chamados desviantes, bastaria reparar em certas pessoas que não entram em consonância com o mundo dos adequados, adaptados, produtivos; assim, estabelece-se o conflito entre o mundo de uma criatura meio dispersa, que não consegue inserir sua produção no contexto da produção dominante.

Se, no caso, o trabalho de quem presta ajuda aos alunos com "problemas escolares" partisse da premissa do conflito entre mundos, a compreensão que ele vai ter sobre as dificuldades de aprendizagem ou da enfermidade mental, por exemplo, vai ser diferente. Nessa perspectiva de análise, podese dizer que o psicólogo escolar seria um profissional de referência que cria vínculo terapêutico situacional (Campos, 1999). Assim sendo, a intervenção psicológica afunila-se sobre um tipo de atuação vigente na infraestrutura que tece o cotidiano da vida escolar, incidindo no mecanismo básico que opera, não deixando abandonadas à própria sorte as crianças com dificuldades.

Esse tipo de acompanhamento direciona o olhar para a situação atual da criança, modifica os vínculos desde o momento em que um novo saber emerge como estratégia de entendimento, como prática e como acontecimento intersubjetivo, o que tornaria o fazer do psicólogo diferenciado dos outros profissionais que também estão envolvidos na promoção da saúde dentro da escola: a compreensão e o esclarecimento da situação, no momento mesmo em que ocorre o processo de "enfermar" e de excluir a criança do ensino escolarizado. Esse é um fato que ocorrerá não porque os professores se sintam "vigiados", mas, fundamentalmente, porque 
não se encontram mais sozinhos: o sentimento altruísta de ajuda se incorpora, novamente, à prática de ensinar.

Trabalhando não somente como assessor, que, sem dúvida, é uma parte importante do trabalho do psicólogo escolar, mas interagindo com as crianças e o professor, comunicandose, diretamente, com a família e outros técnicos, introduz-se uma nova dinâmica na própria estrutura de base (escola) do sistema, onde, na realidade, joga-se com as coisas imaginadas e idealizadas por quem planifica a educação. Atuando indiretamente sobre a epistemologia estancada na especialidade tecnocrática, determinante de funções e normas que prescrevem os limites do que deve ser feito individualmente, de acordo com certo ordenamento e estatuto atribuído ao professor, reeducador, psicopedagogo, psicólogo, orientador educacional e outros, surge a oportunidade de introduzir um operador de mudança mediante uma forma de agir concreta e interativa que mobiliza, radicalmente, a comunicação como veículo de mudança de perspectiva em relação aos alunos.

O conceito de propedêutica, nesse contexto educativo, enfatiza a atuação em seu valor como acompanhamento empático, adaptado à realidade escolar. Essa atuação tem função de dispositivo facilitador da abordagem pedagógica dos problemas escolares que afetam, no caso, estudantes das camadas pobres da população. Essa propedêutica caracteriza não só um trabalho sobre o "problema de aprendizagem", mas também sobre os problemas emocionais que surgem durante o processo de aprendizado escolar. O trabalho é conduzido por meio das intervenções do pesquisador, que se realizam de forma conjunta com as professoras no contexto da escola pública.

Foi a nossa preocupação com a existência "abandonada" do aluno que comunicamos às professoras, no início da pesquisa, como intenção deste estudo; por isso, o diálogo com as professoras revestiu-se de nuances particulares. Sabíamos, pela experiência, que a nossa atuação na escola somente viria ser plenamente aceita no momento em que pudéssemos convencê-las de que não teríamos como objetivo interferir no seu trabalho, avaliar o método pedagógico ou o conteúdo das matérias, mas, sim, buscar formas de poder ajudar aos alunos que supuséssemos ter uma defasagem entre o rendimento atual e o potencial de aprendizagem, pois esse bloqueio os faz sentirem-se fracassados na aprendizagem e nas relações interpessoais, afetando a intimidade e a representação social que eles têm de si mesmos.

A "inibição" (Categoria) fora abordada por Freud (1968) em 1925, no texto "Inibição, Sintoma e Angústia"; é descrita como uma restrição funcional do ego, uma limitação, exclusivamente, em nível do ego, que podia obedecer a distintas causas, mas não significaria, necessariamente, algo patológico, salvo se a inibição fosse parte da formação de um sintoma. Nesse último caso, como os sintomas são processos que não ocorrem no ego, renunciar à aprendizagem escolar seria um meio de evitar a angústia que provém de um conflito de outra natureza (edípica, provavelmente). O mecanismo inconsciente de deslocamento faria com que as representações eróticas passassem a estar ligadas às tarefas escolares, estabelecendo-se, 
dessa maneira, a "absurda" relação entre o não aprender e a neurose. Para Freud, a inibição aconteceria em três situações: quando há uma erotização dos órgãos comprometidos em determinada ação, por exemplo, a inabilidade manual associada à masturbação; quando o ego não se permite o êxito ou a compulsão ao fracasso, porque o êxito é proibido por um superego tirânico, ou quando o ego está inibido de maneira geral, por estar absorvido no labor psíquico do luto, da depressão ou da melancolia.

A extrapolação da questão pedagógica dos “problemas de aprendizagem" para o campo clínico da Psicopedagogia está presente nos estudos de Pain (1992), sob o tema da reação neurótica ante a proibição da satisfação instintiva; nos trabalhos de Fernández (1991), como problema de inibição cognitiva, e nos escritos de Bleichmar (1994), no domínio da inibição primária não relacionada a um sintoma. Cordié (1996) acrescenta a noção de que a inibição da aprendizagem pode estar relacionada à incorporação de um modelo humano como ideal ou com a identificação com um valor moral, religioso ou outro, que implicaria renúncia a todos os ideais propostos pela sociedade em forma de sucesso e felicidade.

Porém, podemos interpretar de outra maneira a inibição observada nos participantes de pesquisa.

Quem sofre o fracasso escolar prolongado se inibe ao sentir alterada uma parte do campo significativo da vida (vivência), em razão de que se instala, no horizonte do mundo vivido, o sentimento de impotência e menosprezo que vem cercear a possibilidade de revelar, por si mesmo, a experiência conforme experimentada. O aluno passa a não se interrogar mais sobre o futuro desejado nem sobre a sua situação atual no mundo, não procura saber qual é a escatologia que funda seu ser, que se desqualifica como aprendiz.

Do ponto de vista existencial, a inibição dos participantes da pesquisa pode ser compreendida com base na situação ontológica do aluno, pois trata-se de existências atadas à angústia que o ato de aprender frustrado desperta, que se arrasta esvaziando a alegria do aluno, aula após aula, encontrando como saída para esse drama a impostura de ficar anônimo em classe por ter comprovado sua eficácia como defesa ideal para continuar pertencendo à escola, mesmo que excluído dos olhares de quem (professores e psicólogos) deveria estar próximo dele (aluno).

Pode-se imaginar o que é passar dia após dia dessa maneira?

A forma como era experimentado o tempo e o espaço de sala de aula, e a distância, imposta nas relações interpessoais, lembra-nos "um modo existencial anônimo". No começo do acompanhamento, os alunos adotavam a "impostura" como mecanismo de defesa para poder acomodar-se em sala de aula; permaneciam num silêncio total, quase imóveis em classe, escrevendo e apagando, reiteradamente, uma palavra ou uma frase que, às vezes, nada tinha a ver com o tema proposto pela professora, de modo que, se alguém os olhasse à distância, perceberia nada mais que alunos bem comportados e empenhados na realização dos trabalhos escolares. Tratava-se de uma atitude do aluno relacionada à experiência escolar que refletia como eles se sentiam como alunos, 
diferentemente, por certo, do que a professora e eu observávamos no modo como essas mesmas crianças eram e se sentiam no recreio ou fora da escola. Tínhamos visto esses alunos desfrutar da companhia de amigos, participar das brincadeiras, conversar animadamente... Dessa forma, não somente a defasagem entre o rendimento escolar e o potencial para o aprendizado caracterizava os participantes de pesquisa, mas, principalmente, o "intervalo" Eu-Tu (Buber, 1977) era o que estava comprometido, relacionado à situação ontológica da falta de sentido de o sujeito estar na escola. Na inibição predomina a apatia, a "insegurança" e o "distanciamento", bem diferente da dinâmica imposta pelos alunos com traços psicóticos de personalidade; nestes últimos, predomina a euforia e a oposição acirrada à demanda do professor e à do psicólogo, pois quem detém o "saber" é o aluno, que organiza a realidade de maneira onipotente a partir de referenciais subjetivos. Os problemas metapsicológicos não eram simples de entender, porque tudo parecia estar aí: a deficiência mental, os distúrbios neurológicos, os problemas de aprendizagem, mas estávamos cientes de que não era o diagnóstico psicológico de uma doença o que importava, nem a diferenciação de sintomas primários ou secundários para elaborar uma estratégia de intervenção na escola.

A categoria "empatia" interroga: Como foi a postura do pesquisador, no seu trabalho, dentro da escola pública?

Pelo manejo do instrumento acompanhamento e compreensão empática, visando à verdade relacional e à emergência da vivência, apresenta-se a postura do pesquisador. Tratarse-ia de uma atuação que não tem espaço ou momento único como setting, mas uma postura dinâmica "com efeito" terapêutico, porque faz afluírem novos sentidos no cerne de uma formação social (escola), uma escuta e uma ação que se tornam significativas quando se ajusta às vicissitudes que cada criança apresenta e modifica o que foi imaginado pelo entorno sobre o aluno "diferente".

Por meio dessa estratégia, acreditamos na transformação que pode ser operada na dinâmica do dia a dia da escola. Podemos definir o efeito que produz no aluno o encontro com o psicólogo, seguindo a reflexão de Bollnow (1971), como uma descoberta que permite ao sujeito vir a ser "ele-mesmo". Eis que o interagir do pesquisador na escola defronta o aluno, de maneira imprevista, com algo diverso daquilo que ele (aluno) podia prever e se orientar, de acordo com seus mecanismos de defesa, criados durante sua longa experiência de fracasso escolar. Assim sendo, o encontro é um acontecimento destacado, que vem "sacudir" o aluno e exigir-lhe-á orientar-se fora da linha de comportamento seguida até então, mas que não lhe diz em que direção ele deve mudar sua atitude na escola.

O termo encontro significa, também, compreender e valorizar o aluno. É nesse aspecto que se deve compreender o acompanhamento dos alunos no contexto da escola. Não se pretende "curar" ou levar, efetivamente, o aluno a superar o fracasso escolar, mas produzir um efeito de encadeamentos e desencadeamentos de sentido sobre a vivência da situação atual na escola, desinibindo, ordenando e reconciliando a história do aluno com a história do sujeito-criança. 
Fundamentalmente, investigamos as novas representações que se projetaram sobre a existência dos alunos com dificuldades primárias de aprendizagem quando o labor do pesquisador valorizava o encontro humano, no próprio contexto da escola pública, onde se desenvolveu um trabalho junto às professoras buscando promover a saúde coletiva.
Esses conceitos fenomenológico-existenciais influíram para que optássemos pela utilização da técnica de observação participante porque ela oportuniza a criação do princípio ético de respeito mútuo, que permite, por um lado, a colaboração dos atores sociais e, por outro, a possibilidade do o pesquisador devolver a esses atores o que foi percebendo no transcurso do processo de investigação.

Essa técnica, com o tempo, tomou a forma de um acompanhamento no qual a compreensão empática constitui a essência instrumental de uma postura profissional que pretendia servir como mediador humano quando a inibição intelectual e o fracasso escolar caracterizam uma situação do aluno na escola, construída ao longo do tempo. A estratégia de acompanhar o aluno na escola exigiu a iniciativa de criar um espaço singular de diálogo, que surgiu da paciência em esperar um sinal que veio do aluno ou, por parte da professora e do pesquisador, de tornar determinadas atitudes ou iniciar temas de conversação. Essas oportunidades são, às vezes, muito sutis, e foram surgindo num momento qualquer do quotidiano escolar, mas tiveram o peso de realidade psicológica. Esse é o fato que inaugura um momento concreto, um momento interpessoal vivido que serviu como ponto de partida para falar ao aluno sobre seu modo de ser, no aqui e agora da escola. Nesse aspecto, a sensibilidade funcionou como um catalisador que vinculou as coisas que o aluno disse, criou e manifestou à abertura perceptiva propiciada. Trata-se da emergência de percepções que não têm forma, nem nome, mas que serviram de orientador perceptivo de interpretações posteriores.
Mais do que tudo, esse procedimento de observação participante consistiu em uma estratégia que trazia implícita a concepção que temos sobre a importância da comunicação humana para a existência, em sua face de saúde ou de doença. Fundamentalmente, investigamos as novas representações que se projetaram sobre a existência dos alunos com dificuldades primárias de aprendizagem quando o labor do pesquisador valorizava o encontro humano, no próprio contexto da escola pública, onde se desenvolveu um trabalho junto às professoras buscando promover a saúde coletiva.

Nessa investigação, buscamos redimensionar os instrumentos de acordo com o contexto em que trabalhamos. A transferência, por exemplo: podemos pensá-la não somente como transferência imaginária, necessária para a dissolução do "enigma" inconsciente de um passado mítico, que causa a perturbação neurótica, mas podemos limitar-nos a manejar a transferência tal qual ela é entendida por Dolto (1989), como uma forma de conduzir o vínculo com o aluno não para provocar a rememoração de um passado distante, mas para mostrar-lhe o seu modo de funcionamento mental e emocional, a maneira como ele age em relação à aprendizagem escolar, a reação que seu comportamento provoca no professor e nos colegas e as conseqüências desses fatos na sua vida escolar. Nesse contexto, o que interessa, realmente, ao pesquisador, é o que se depreende da comunicação com a criança, com os professores, no aqui e agora da escola, que se metaboliza como encontro humano, momento único e não repetível. Eram esses instantes de efeito perceptivo e afetivo o que eu comunicava ao aluno, ao professor e aos 
pais dos alunos quando pude conversar com eles, e isso veio produzir uma série de remanejamentos representacionais que, talvez, tenham mudado a maneira de pensar e as atitudes das pessoas envolvidas com os problemas de aprendizagem escolar.

O mesmo processo de ajuste ao contexto deve ser feito com o termo interpretação, comumente manejado pelo psicólogo para produzir um efeito significativo sobre a trama das representações do cliente. Dolto (1996), de maneira diferente, concebe a interpretação como um ato analítico comum, não como uma intervenção que pontua um momento crucial nem como uma operação que evidencie uma construção do paciente depois de uma longa elaboração. Essa autora fala de interpretação espontânea para referir-se a uma espécie de ficção que se estabelece a partir da sensação que o comportamento da criança provoca no analista.

As pontuações que, junto com a professora, fazíamos ao aluno, por exemplo, não eram interpretações que buscavam alcançar o mecanismo inconsciente que inibe os esquemas de ação e a inteligência do aluno, ou relacionado ao desvelamento do lugar que ocupa a ignorância no núcleo familiar, às vezes responsável pelas dificuldades de aprendizagem. A "ficção", se assim se pode dizer, criada pela entrada e a participação do pesquisador junto aos outros atores sociais no cotidiano escolar, tem a ver com a inauguração de um campo perceptivo necessário para acolher o sentido das "diferenças individuais", "os modos de ser" dos alunos.

É possível dizer que a atuação deste pesquisador transformou o status quo vigente?
Quando o pesquisador acompanha a criança na escola, surge a possibilidade in situ de promover instâncias que levem o aluno a se perguntar sobre esse outro que se interessa por ele, dando lugar, dessa maneira, ao deslocamento do sentido dado pelo eu mediante um mecanismo de inibição; propiciase o surgimento da demanda como pedido de ajuda que a criança poderia fazer, no aqui e no agora da escola.

Encontrar uma maneira empática de comunicação foi o nosso objetivo, nascido do encontro humano. Portanto, nessa estratégia adotada, não se tratou de entender as palavras ou os sintomas numa relação linear de significação, porque, no contexto de sala de aula e na escola, em geral, a questão que decide determinadas atitudes é, às vezes, alguma coisa que vem da criança: um olhar, um gesto, mas que não é, em si, um traço visível, porém, desperta em nós um olhar interno e nos faz sentir o que o outro tem de mais próprio.

Fica claro, para nós, que a práxis de acompanhamento na escola foi centrada no presente fáctico, na relação atual com a criança, de modo que o que valeu, realmente, foi o vínculo dinâmico presente com o pesquisador, com as professoras e com os colegas. Esse modo de trabalhar na escola permitiu atuar no momento mesmo em que ocorreram as dificuldades escolares, sem ficarmos preso à norma do encaminhamento, que estipula a necessidade de recapitular, sempre, de re-atualizar ou mediatizar a experiência vivida pela criança, em outro setting e em outro momento, a posteriori.

Enfim, no que se refere à ocorrência de modificações de alguns dos comportamentos dos alunos participantes desta pesquisa, seria 
presunçoso dizer que a produção intelectual tenha melhorado, notavelmente, mas seria injusto omitir que a produção gráfica e plástica no atendimento na Sala de Integração e Recursos melhorou, assim como a comunicação com as professoras de educação especial e com a professora de sala de aula e os colegas foi transformada.

\section{Considerações não conclusivas}

É necessário ao psicólogo escolar apropriar-se de uma forma de trabalho sem a priori técnico, porque não é somente o caráter técnico nem o embasamento teórico o álibi que, às vezes, produz mudanças no comportamento das pessoas, mas o encontro humano com o mundo vivido do outro, com a existência;

A compreensão do fracasso escolar e das dificuldades de aprendizagem exigem ir além da "escuta" e do diagnóstico de uma patologia;
O sentido de experiência vivida fundamenta um estilo de trabalho possível, uma atuação propedêutica à intervenção pedagógica; nesse sentido, foi essencial o diálogo e o trabalho conjunto entre a professora de sala de aula, as professoras das Salas de Integração e Recursos (SIR) e o pesquisador, conformando, dessa maneira, dentro da escola, um campo de atuação interdisciplinar;

Na prática, a compreensão empática é o instrumento que possibilita operacionalizar a relação intersubjetiva a partir de uma atitude sensível e intuitiva, diferente da perspectiva causal e concreta de compreender o problema do aluno.

O acompanhamento dos alunos mostrou ser este um agir diferente e, ao mesmo tempo, complementar à abordagem institucional atualmente desenvolvida pelo psicólogo vinculado à escola pública.

Elbio Nelson Cardoso Guardia Psicólogo pela Universidade da República Oriental do Uruguai Mestre em Saúde Coletiva Professor de Graduação e Pós-Graduação na Faculdade da Serra Gaúcha - FSC Rua Riachuelo, 1521 / 302 . Porto Alegre- RS. CEP: 90010271- Centro Fone: (051) 3225-70-65

E-mail: nelsongu@terra.com.br 
BARDIN, L. Análise de Conteúdo. Trad.: Luis Antero Reto e Augusto Pinheiro. Lisboa: Edições 70, 1977.

BAREMBlitT, G. A Rua como Espaço Clínico. Equipe de Acompanhantes Terapêuticos do Hospital Dia A CASA. São Paulo: Escuta, 1991

BLEICHMAR, S. A Fundação do Inconsciente. Trad.: Kênia Ballvé Beher. Porto Alegre: Artes Médicas, 1994.

BOLLOW, O. Pedagogia e Filosofia Existencial: um Ensaio sobre Formas Instáveis da Educação. Trad.: Hermógenes Harada. Petrópolis: Vozes, 1971.

BONAMIGO, E; BRISTOTI, N. Enriquecimento Verbal em Crianças Marginalizadas. Cadernos de Pesquisa da Fundação Carlos Chagas, n.24, março, 1978.

BUBER, M. Eu e Tu. Trad.: Newton Aquiles Von Zuben. São Paulo: Cortes \& Moraes, 1977.

BUSNELLO, A. A Integração da Saúde Mental num Sistema de Saúde Comunitária. Porto Alegre: Editora da UFRGS, 1975.

CAMPOS, W. Equipes de Referência e Apoio Especializado Matricial: um Ensaio sobre a Reorganização do Trabalho em Saúde. Revista Ciência \& Saúde Coletiva, v. 4, 2, 1999.

CORDIÉ, A. Os Atrasados não Existem. Psicanálise de Crianças com Fracasso Escolar. Trad.: Sônia Flach e Marta D’Agord. Porto Alegre: Artes Médicas, 1996.

DOLTO, F. Dialogando sobre Crianças e Adolescentes. Trad.: Maria Nurymar Brandão Banetti. Campinas: Papirus, 1998.

. Françoise Dolto ou a Interpretação Espontânea. In Os Poderes da Palavra: Textos Reunidos pela Associação Mundial de Psicanálise. Rio de Janeiro: Zahar, 1996.

ENGUITA, M. A Face Oculta da Escola. Trad.: Tomaz Tadeu da Silva. Porto Alegre: Artes Médicas, 1989.

FERNÁNDEZ, A. A Inteligência Aprisionada: Abordagem Psicopedagógica Clínica da Criança e sua Família. Trad.: Iara Rodrigues. Porto Alegre: Artes Médicas, 1991.

FONSECA, V. Introdução às Dificuldades de Aprendizagem. 2. Edição. Porto Alegre: Artes Médicas, 1995.
FOUCAULT, M. Microfísica do Poder. 2. ed. Trad.: Roberto Machado. Rio de Janeiro: Graal, 1981

A Verdade e as Formas Jurídicas. 2.ed. Trad.: Roberto Cabral de Mello Machado e Eduardo Jardim Morais. Rio de Janeiro: NAU, 1999.

FREUD, S. Inibição, Sintoma y Angustia. Obras Completas. Trad.: Luis Lopez- Ballesteros y de Torres. Madrid: Biblioteca Nueva, v.2, 1968, p.31.

LIMA, Z. Saúde Escolar e Educação. São Paulo: Cortez, 1985. MACHADO, R.; LOUREIRO, A.; Luz, R. et al. Danação da Norma. Medicina Social e Constituição da Psiquiatria no Brasil. Rio de Janeiro: Graal, 1978.

MALINOWSKI, B. "Tema Método e Objetivo desta Pesquisa". Argonautas do Pacífico Ocidental: um Relato do Empreendimento e da Aventura dos Nativos nos Arquipélagos da Nova Guné, Melanésia. Trad.: Anton P. Carr e Ligia Aparecida Cardieri Mendonça. São Paulo: Abril Cultural, 1984. Os Pensadores.

MONTOYA, D. De que Modo o Meio Social Influi no Desenvolvimento Cognitivo da Criança Marginalizada?. Dissertação de Mestrado em Psicologia-Instituto de Psicologia. Universidade de São Paulo. In Patto, Maria Helena. Cadernos de Pesquisa da Fundação Carlos Chagas, n. 51, 1984, p. 7 .

MOYSÉS, A; LIMA, Z. Desnutrição e Fracasso Escolar: uma Relação tão Simples? In Revista da Associação Nacional de Educação (ANDE) Ano1, n. 5, 1982.

MOYSÉS, A; COLLARES, A. A História não Contada dos Distúrbios de Aprendizagem. In Cadernos CEDES: Centro de Estudos Educação e Sociedade, n.28. Campinas: Papirus, 1992.

PAIN, S. Diagnóstico e Tratamento dos Problemas de Aprendizagem. 4. ed. Trad.: Ana Maria Netto Machado. Porto Alegre: Artes Médicas, 1995.

POPPOVIC, M. Alfabetização: Disfunções Neuropsicológicas. São Paulo: Vetor, 1968.

RAMOZZI-CHIAROTTINO, Z. Em Busca do Sentido da Obra de Jean Piaget: Pequena Contribuição para a História das Idéias e para a Ação do Psicólogo num País de Contrastes. Tese Livre-Docência. Instituto de Psicologia. Universidade de São Paulo. São Paulo: mimeo, 1982.

ROMANELLI, O. História da Educação no Brasil. 26. ed. Petrópolis: Vozes, 2001.

\section{Referências}

